\title{
Conf-910869--27
}

Reringul Oon

FEB 241992

GA-A--20694

DE9 2008052

\section{FAST WAVE CURRENT DRIVE ANTENNA PERFORMANCE ON DIII-D}

by

M.J. MAYBERRY, R.I. PINSKER, S.C. CHIU, G.L. JACKSON, S.I. LIPPMANN, M. PORKOLAB, R. PRATER, F.W. BAITY, R.H. GOULDING, and D.J. HOFFMAN

OCTOBER 1991

\section{GENERAL ATOMIES}




\section{DISCLAIMER}

This report was prepared as an account of work sponsored by an agency of the United States Government. Neither the United States Government nor any agency thereof, nor any of their employees, makes any warranty, express or implied, or assumes any legal liability or responsibility for the accuracy, completeness, or usefulness of any information, apparatus, product, or process disclosed, or represents that its use would not infringe privately owned rights. Reference herein to any specific commercial product, process, or service by trade name, traclemark, manufacturer, or otherwise, does not necessarily constitute or iñply its endorsement, recommendation, or favoring by the United States Government or any agency thereof. The views and opinions of authors expressed herein do not necessarily state or reflect those of the United States Government or any agency thereof. 
GA-A20694

\title{
FAST WAVE CURRENT DRIVE ANTENNA PERFORMANCE ON DIII-D
}

\author{
by \\ M.J. MAYBERRY, R.I. PINSKER, S.C. CHIU, G.L. JACKSON, \\ S.I. LIPPMANN, M. PORKOLAB,* R. PRATER, F.W. BAITY, ${ }^{\dagger}$ \\ R.H. GOULDING, ${ }^{\dagger}$ and D.J. HOFFMAN ${ }^{\dagger}$
}

This is a preprint of a paper presented at the Ninth Topical Conference on the Radio Frequency, August 19-21, 1991, in Charleston, South Carolina, and to be printed in the Proceedings.

Work supported by

U.S. Department of Energy

Contract Nos. DE-AC03-89ER51114 and DE-AC05-840R21.400

* Plasma Fusion Center, MIT, USA.

† Oak Ridge National Laboratory, USA.

\section{GENERAL ATOMICS PROJECT 3466 OCTOBER 1991}

\section{geNeral ATOMICS}

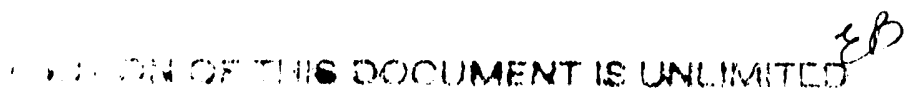




\title{
FAST WAVE CURENT DRIVE ANTENNA PERFORMANCE ON DIII-D*
}

\author{
M.J. Mayberry, R.I. Pinsker, C.C. Petty, S.C. Chiu, G.L. Jackson, \\ S.I. Lippmann, M. Porkolab, ${ }^{\dagger}$ R. Prater \\ General Atomics, P.O. Box 85608, San Diego, California 92138-5608 \\ F.W. Baity, R.H. Goulding, D.J. Hoffman \\ Oak Ridge National Laboratory, Oak Ridge, Tennersee 37831
}

\section{INTRODUCTION}

Fast wave current drive (FWCD) experiments at $60 \mathrm{MHz}$ are being performed on the DIII-D tokamak for the first time in high electron temperature, high $\beta$ target plasmas. A four-element phased-array. antenna ${ }^{1}$ is used to launch a directional wave spectrum with the peak $n_{\|}$value $(\simeq 7)$ optimized for strong single-pass electron absorption due to electron Landau damping. ${ }^{2}$ For this experiment, high power FW injection (2 MW) must be accomplished without voltage breakdown in the transmission lines or antenna, and without significant impurity influx. In addition, there is the technological challenge of impedance matching a four-element antenna while maintaining equal currents and the correct phasing $\left(90^{\circ}\right)$ in each of the straps for a directional spectrum. In this paper we describe the performance of the DIII-D FWCD antenna during initial FW electron heating and current drive experiments in terms of these requirements.

\section{ANTENNA LOADING AND POWER HANDLING}

The present if transmitter can provide up to $2.0 \mathrm{MW}$ of $60 \mathrm{MHz}$ power at pulse lengths up to $10 \mathrm{~s}$. To date, up to 1.6 MW net power has been delivered to the FWCD antenna with $(0, \pi, 0, \pi)$ phasing. Up to $1.2 \mathrm{MW}$ net power has been delivered to the antenna with asymmetric $(0,-\pi / 2,-\pi,-3 \pi / 2)$ phasing for current drive. At present, the system power limit appears to be due to a voltage limit $(\sim 25 \mathrm{kV})$ in the transnission line tuners rather than a voltage or power density limit at the antenna.

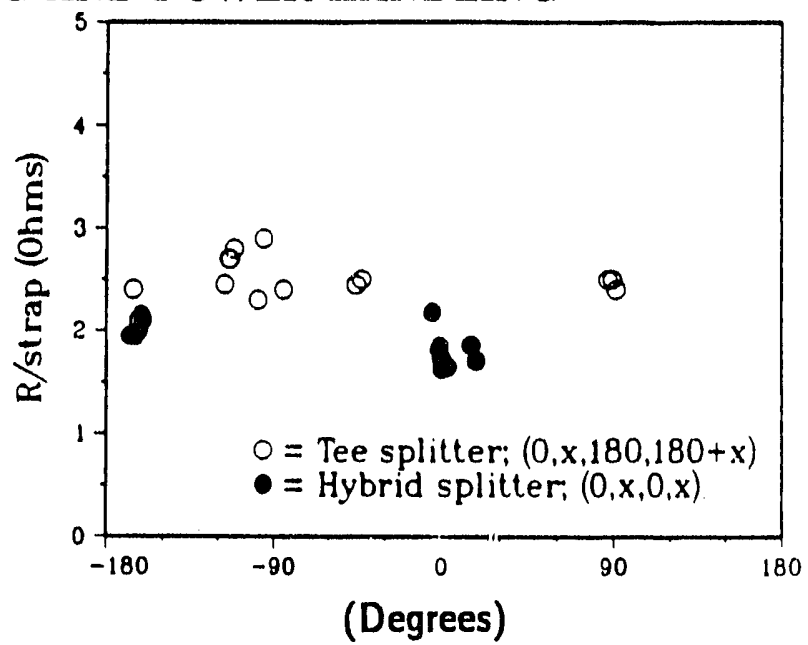

Fig. 1. Antenna loading resistance per strap for several phasings.

The dependence of the antenna loading on the antenna phasing is shown in Fig. 1 for divertor discharges with line average electron densities of about $2 \times 10^{13} \mathrm{~cm}^{-3}$ and gaps between the plasma and the antenna of about $2 \mathrm{~cm}$.

* Work supported by the U.S. Department of Energy under Contract Nos. DE-AC0389 ER51114 and DE-AC05-84OR21400.

$\dagger$ Plasma Fusion Center, MIT, Cambridge, Massachusetts 02139 
There is a slight peaking of the loading at $(0, \pm \pi / 2, \pm \pi, \pm 3 \pi / 2)$ phasing, but generally a weak dependence of loading on phasing is observed. At the lower target densities $\left(\bar{n}=1-1.5 \times 10^{13} \mathrm{~cm}^{-3}\right)$ expected to be used in upcoming FWCD experiments on DIII-D, the antenna loading resistance is expected to be somewhat lower ( $R \simeq 1.3 \Omega /$ strap); the corresponding voltage requirement in the transmission lines for a $2 \mathrm{MW}$ power level is $32 \mathrm{kV}$.

\section{IMPURITY CONTROL USING WALL CONDITIONING}

Sputtering of metallic impurities due to the formation of $\mathrm{ff}$ sheaths near the antenna is a potential concern when the antenna is phased for current drive since If flux contributions from adjacent current straps in the antenna do not cancel. ${ }^{3}$ However, coating the antenna and nearby tokamak vessel wall surfaces with low- $Z$ materials is found to be effective in reducing metal influx and radiated power. Various wall coating techniques have been evaluated on DIII-D including carbonization and boronization (using diborane gas).

Boronization is found to be the most effective wall conditioning technique, but only if the local coverage is good near the FWCD antenna. If diborane gas is injected from the opposite side of the torus from the FWCD antenna (resulting in poor coverage near the antenna), then neither metal influx nor the increase in radiated power during $\mathrm{rf}$ injection are reduced significantly. Under these conditions (BZN1), we find higher impurity influx with $(0,0,0,0)$ or $(0, \pi / 2,0, \pi / 2)$ phasing compared to $(0, \pi, 0, \pi)$ phasing, as well as a factor of two higher level of incremental radiated power $\left(\Delta P_{\text {rad }} / P_{\mathrm{rf}} \simeq 2 / 3\right.$ versus $\left.1 / 3\right)$. Boronization with the diborane gas injected directly through the FWCD antenna port (BZN2) is much more effective in controlling impurities, as shown in Fig. 2.

Most of the FW electron heating results $\left(P_{\mathrm{If}} \leq 1.6 \mathrm{MW}\right)$ reported at this conference ${ }^{4}$ were obtained with the DIII-D vessel walls and FW antenna coated via carbonization (CZN). While this technique substantially reduces the metallic impurity influx during $\mathrm{ff}$, it is not as effective as a good boronization (BZN2) in reducing radiated power. This is apparently a result of the substantial carbon influx observed during FW injection after carbonization. Nevertheless, relatively small increases in radiated power have been obtained with this technique as shown in Fig. 3. Typically, we find $\Delta P_{\text {rad }} / P_{\mathrm{rf}} \simeq 0.3$ with carbonization, independent of the antenna phasing. As the coverage of the carbonization is expected to be good near the FW antenna, these results show that impurity influx can be controlled with effective wall conditioning near the antenna, even with asymmetric antenna phasing.

\section{ANTENNA TUNING}

A scheme has been developed for impedance matching the four-element FWCD antenna which allows $\pm 90^{\circ}$ phasing to be maintained for current drive (or anti-CD) with equal currents in each of the four straps. ${ }^{1}$ Because of the mutual coupling between adjacent current straps, it is necessary to feed unequal power levels to the four straps in order to achieve equal currents. In the DIII-D system (diagram in Ref. 1), this problem is simplified by connecting alternate straps $(1-3,2-4)$ together with resonant lines ( 6 inch diameter, $Z_{0}=25.7 \Omega$ ), 
thus ensuring equal antenna currents in alternate straps which are either inphase or out-of-phase, depending on the resonant line length. Each resonant circuit is fed by a 9 inch diameter, $50 \Omega$ line at the high voltage point. Since only two input lines must be tuned, the impedance matching problem is reduced to that of an equivalent two-element antenna which can be characterized by a $2 \times 2$ input admittance matrix with elements $Y_{A A}$, $Y_{A B}, Y_{B A}, Y_{B B}$ (A and $B$ denote the two feed lines). Specifying the voltage ratio (magnitude and phase) at the locations of the tees is equivalent to specifying the current ratios between adjacent antenna straps because of the resonant line configuration.

By assuming antenna symmetry $\left(Y_{A A}=Y_{B B}, Y_{A B}=Y_{B A}\right)$, the elements of the antenna admittance matrix can be determirued in a single shot by measuring the input admittance in each feed line and the voltage ratio at the tees. The required input admittances at the tees are given by:

$$
\begin{aligned}
& Y_{A}^{\text {tee }}=Y_{A A}+Y_{A B}\left(\frac{V_{B}}{V_{A}}\right)^{\text {tee }} \\
& Y_{B}^{\text {tee }}=Y_{B B}+Y_{B A}\left(\frac{V_{A}}{V_{B}}\right)^{\text {tee }}
\end{aligned}
$$

where $\left(\frac{V_{B}}{V_{A}}\right)^{\text {ree }}= \pm j$ for current drive or anti-CD phasing. In order tc allow unequal power levels in each feed line, an unmatched tee splitter is used at the transmitter to divide the power. The input admittance on each side of the tee splitter must satisfy the following:

$$
Y_{A}^{\mathrm{in}}+Y_{B}^{\mathrm{in}}=Y_{0}=1 / Z_{0}
$$

such that

$$
\frac{P_{\text {netA }}}{P_{\text {netB }}}=\frac{\operatorname{Re}\left(Y_{A}^{\mathrm{in}}\right)}{\operatorname{Re}\left(Y_{B}^{\mathrm{in}}\right)}=\frac{\operatorname{Re}\left(Y_{A}^{\text {tee }}\right)}{\operatorname{Re}\left(Y_{B}^{\text {tee }}\right)}\left|\frac{V_{A}^{\text {tee }}}{V_{B}^{\text {tee }}}\right|^{2} .
$$

Once these quantities are specified, the five tuner settings are determined.

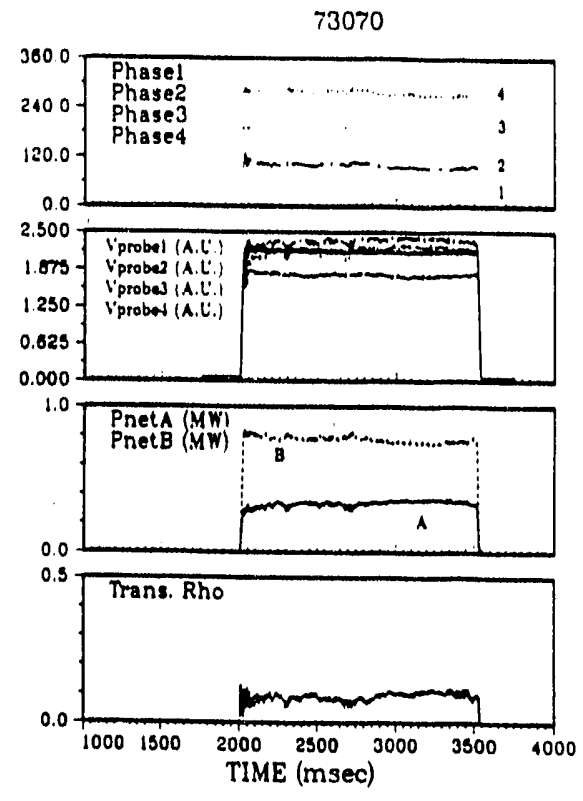

Fig. 2.Time history of impurity influx during FW injection for BZNI (dashed curve) and BZN2 (solid curve). A $1 \mathrm{MW}$ neutral beam pulse is also shown for comparison $\left(I_{p}=1 M A, B_{T}=2 T, \vec{n}=2 \times\right.$ $\left.10^{13} \mathrm{~cm}^{-3}\right)$.

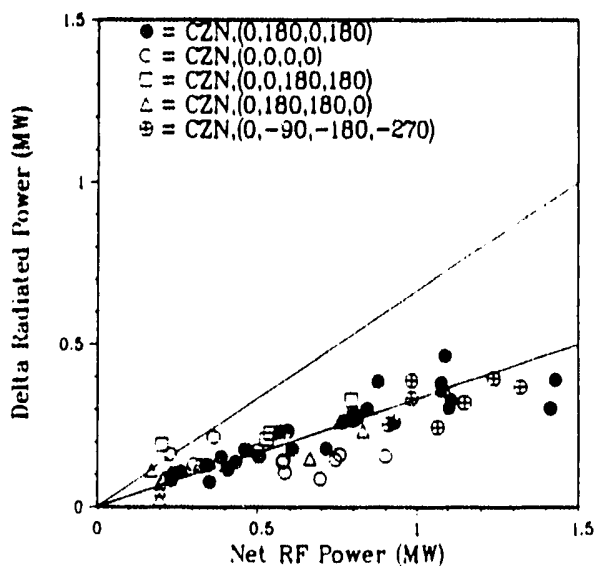

Fig. 3. Incremental radiated power for several phasings after carbonization. 
Using this algorithm, predictive antenna tuning with $\pm 90^{\circ}$ phasing has been achieved. Typical results with $-90^{\circ}$ phasing and 1.25 MW injected power are shown in Fig. 4. The results exhibit the correct relative phasing between the antenna currents and equal current in the four straps. The ratio between net powers in the two feed lines is $P_{\text {netB }} / P_{\text {net }} \simeq 2.4$. The impedance match at the transmitter is excellent, with $P_{\text {ref }} / P_{\text {fwd }} \simeq 1 \%$. Similar results with anti-CD phasing $\left(+90^{\circ}\right)$ were achieved in a single shot, based on measurements from the $-90^{\circ}$ case.

\section{SUMMARY}

Our initial evaluation of the DIII-D FWCD antenna performance indicates that full power injection (2 MW) should be achievable with the observed antenna

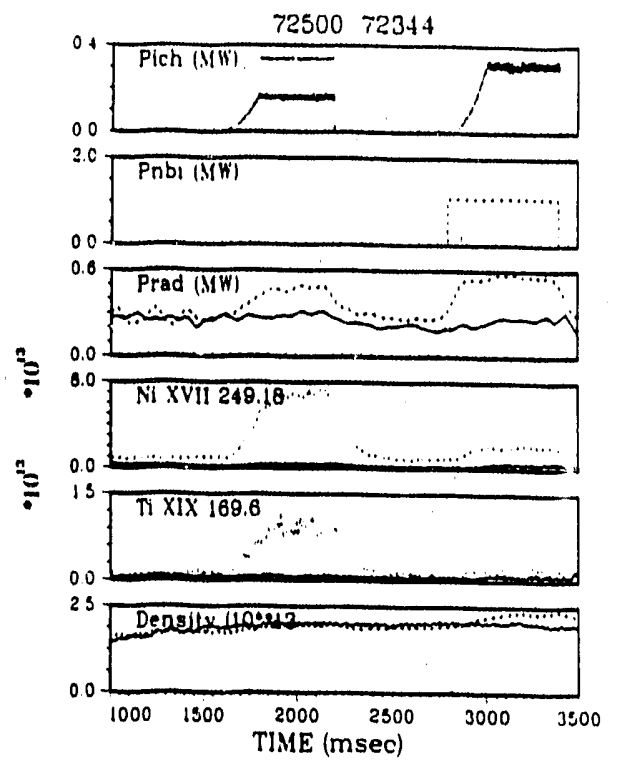

Fig. 4.Four strap antenna phase and voltage, along with net powers in the $50 \Omega$ feed lines during current drive experiments $\left(I_{p}=0.8 M A, B_{T}=2 T, \bar{n}=2 \times\right.$ $10^{13} \mathrm{~cm}^{-3}$ ).

loading once transmission line voltage standoff is improved to the $32 \mathrm{kV}$ level. It appears that metallic impurity influx can be minimized even with asymmetric antenna phasing by wall conditioning (boronization) as long as good wall coverage is obtained near the antenna. Finally, antenna tuning with equal antenna currents and the proper phasing for current drive has been demonstrated using a resonant line configuration and a computer-based predictive tuning algorithm. Thus, all of the requirements on the antenna for efficient CD operation appear to be achievable simultaneously.

\section{REFERENCES}

1 R.H. Goulding, these proceedings.

2 M. Porkolab, these proceedings.

3 D. D'Ippolito, et al., Plasma Phys. Contr. Fusion 33, 607 (1991).

4 C.C. Petty, et al., "Direct electron heating by $60 \mathrm{MHz}$ fast waves on DIII-D," these proceedings. 

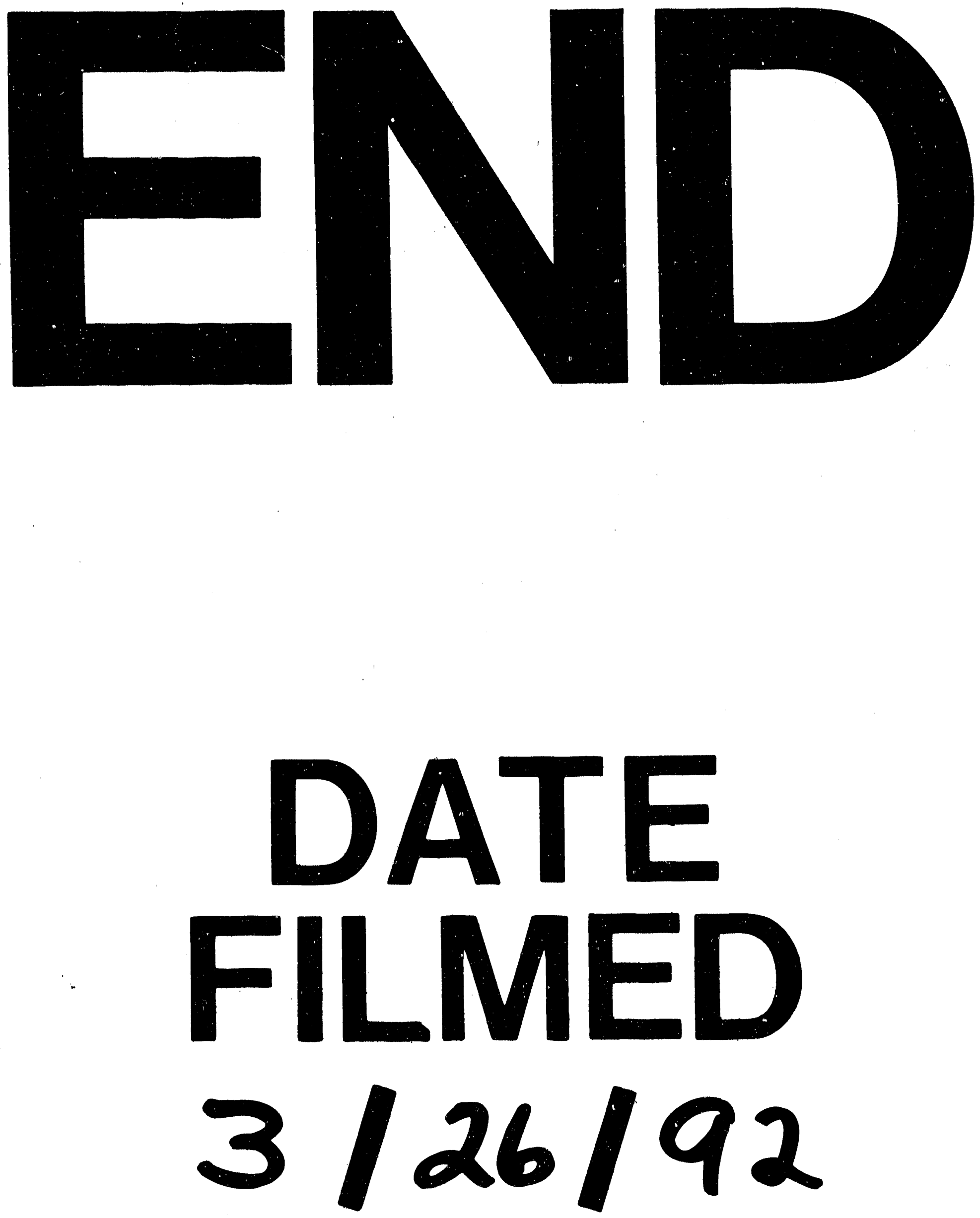
